\title{
Un Centro para Atención de la Adolescente Embarazada
}

\author{
Alberto Rizo G., MD, MSP Elena Prada S., Soc. MSc \\ XIV CONGRESO COLOMBIANO DE OBSTETRICIA \\ $Y$ GINECOLOGIA
}

La presentación siguiente corresponde a la descripción de un proyecto que se realizó en Jamaica, país caribeño, situado al sur de la Isla de Cuba, que ten ía 2 mills. de habitantes según el censo efectuado en 1970. Jamaica, como muchos otros países del hemisferio occidental, presenta un considerable crecimiento de su población pese a los esfuerzos que realiza el gobierno por desacelerar dicho crecimiento. La población de la Isla es bastante heterogénea y predomina el ancestro africano entre sus habitantes.

La alta fecundidad en la población femenina entre los 15 y 19 años de edad es uno de los niayore: retos que enfrentan los gobernantes de Jamaica. Auncuando las cifras del número de nacimientos por 1.000 mujeres entre 15 y 19 años no son de la magnitud de las que se observan en países como Bangladesh (203 por 1.000 mujeres). Jamaica con 160 nacidos por 1.000 mujeres en dicho grupo, es el país con la más alta tasa de fecundidad en el Hemisferio Occidental. Cuadro No. 1.

El problema de la elevada fecundidad en la población adolescente tiene múltiples causas y no constituye objetivo de este trabajo el profundizar sobre ellas. Bástenos decir que la ilegitimidad es
Cuadro No. 1

TASAS DE FECUNDIDAD* EN MUJERES DE 15 - 19 AÑOS EN ALGUNOS PAISES DE AMERICA LATINA Y EL CARIBE

Mayores de 110/1.000 Jamaica Rep. Dominicana Honduras

Entre 100 y 100/1.000 Venezuela Costa Rica

Entre 80 y 100/1.000 Colombia México

Menores de 80/1.000 Chile Argentina

* Número de nacimientos $\times 1.000$ mujeres en el grupo de edad $15-19$.

elevada, el abandono del hogar por parte del padre es bastante común, la pobreza, la deficiente educación, la dificultad para progresar $y$ obtener empleo etc., son constantes en la problemática del subdesarrollo al cual se enfrenta Jamaica al igual que muchos otros países del mundo en desarrollo. Agreguemos a los factores antes enunciados, que la mujer en Jamaica por razones de tipo cultural, debe 
ejercitar su fecundidad aún antes de llegar a completa madurez biológica y casi siempre en circunstancias que no le aseguran una unión estable. Las consecuencias son fáciles de imaginar.

Si la joven mujer estudia y resulta embarazada, debe abandonar sus estudios al igual de lo que sucede en nuestro país.

¿Qué podría hacerse para atenuar un poco la gravedad del problema mientras se actúa sobre las causas que lo producen y las circunstancias que lo agravan?

La oficina de programas de la mujer del gobierno de Jamaica (The Women's Office) con la cooperación de la IPPF/WH y del Pathfinder Fund decidió emprender la búsqueda de algunas soluciones a corto plazo, organizando el centro para la mujer adolescente cuyos objetivos fueron:

1. Proporcionar a la adolescente embarazada, que ha salido del sistema educativo, la asistencia necesaria para continuar su estudio en un lugar seguro y confortable que le permita llevar su embarazo normalmente, prepararse para el parto y continuar una vida más adecuada posible, una vez nazca el niño/a.

2. Facilitar a la adolescente el reingreso al sistema educativo luego de producirse el parto.

3. Para aquellas adolescentes que no desean continuar sus estudios, proporcionarles el entrenamiento necesario en una actividad que les permita obtener empleo $\mathrm{y}$ un ingreso adecuado.

Las adolescentes embarazadas que, acuden al centro son asignadas a uno de dos grupos, según se trate de estudiantes con baja escolaridad o estudiantes que hayan cursado algunos grados. Profesores que prestan sus servicios al centro trabajan con las alumnas en las asignaturas correspondientes al nivel de estudios en el cual estaban matriculadas antes de abandonar la escuela, les ayudan durante el curso del embarazo a continuar y completar el programa para que esten a la par del resto de compañeras. Generalmente 16 horas semanales totales son suficientes para tal fin. La educación para la vida familiar recibe énfasis considerable pues allí se prepara a la futura madre en aspectos tan variados como puericultura, cuidados del embarazo, anticoncepción etc., cuadro No. 2.

Cuadro No. 2

JAMAICA

QUE ESTUDIOS SE SIGUEN EN EL CENTRO PARA LA MUJER ADOLESCENTE

\begin{tabular}{lcc} 
& \multicolumn{2}{c}{ Horas Semanales } \\
& Mañanas & Tardes $^{*}$ \\
\hline Inglés (Gramática) & 2 & 3 \\
Inglés (Literatura) & 2 & 1 \\
Matemática & 2 & 3 \\
Biología & 2 & 1 \\
Historia & 1 & 1 \\
Cívica & 1 & 1 \\
Educación para la & 2 & 3 \\
vida familiar & 2 & 1 \\
Música & 1 & 1 \\
Teatro & 1 & 1 \\
Artesan ías/Culinaria & 1 & 16 \\
\hline TOTAL & 16 & 1 \\
\hline
\end{tabular}

* Grupo avanzado que continuará sus estu. dios en el sistema formal.

** Principiantes 
Las características de las participantes que acuden al centro son las siguientes:

- Edad promedio 15 años.

- Su madre es cabeza del hogar - padre ausente.

- Tiene en promedio 6 hermanos.

- Vive en inquilinato

- Estudiaba cuando se embarazó y desea vivamente continuar sus estudios.

- Desea continuar su embarazo y cuidar de su niño/a después del parto.

- Desea ser maestra, enfermera o secretaria.

- El compañero tiene en promedio 20 años de edad y sus ingresos por lo general son mayores que los del hogar en el cual vive la joven.

(Datos obtenidos mediante encuesta a 53 participantes durante el primer año del proyecto).

Por lo general la adolescente permanece en el centro durante el curso de su embarazo, interrumpe su asistencia unos dias cuando se presenta el parto y durante algunos del puerperio. El centro hace los contactos necesarios con instituciones de asistencia médica para que se preste a la alumna toda la atención que su estado requiere. Luego regresa a completar el curso académico al finalizar este período.

La mayoría de 204 alumnas que asistieron al centro entre abril de 1978 y diciembre de 1979 continuaron sus estudios; pasaron de un curso de educa. ción superior $59 \%, 14 \%$ continuaron un programa de entrenamiento especial. Alrededor de una cuarta parte $(26 \%)$ de las alumnas, o no continuaron sus estudios o se desconocía su destino cuando se realizó el seguimiento. Vale la pena recalcar que 150 de 204 adolescentes estudiadas permanecieron vinculadas a programas educativos o de capacitación especial pese a haberse embarazado y tenido un parto, lo cual supone un cambio trascendental en la vida de cualquier mujer. Cuadro No. 3.

\section{Cuadro No. 3}

SEGUIMIENTO DE JOVENES ADOLESCEN. TES QUE ASISTIERON AL CENTRO ENTRE ABRIL/78 Y DIC./79

\begin{tabular}{|c|c|c|c|c|c|c|c|}
\hline & \multicolumn{5}{|c|}{ Períodos Académicos } & \multicolumn{2}{|c|}{ Total } \\
\hline & 10. & 20. & 3o. & 40. & 50. & No. & $\%$ \\
\hline $\begin{array}{l}\text { Pasaron o continuaron } \\
\text { estudios secundarios }\end{array}$ & 32 & 22 & 18 & 19 & 5 & 96 & 47 \\
\hline $\begin{array}{l}\text { Pasaron a educación } \\
\text { superior }\end{array}$ & 1 & 5 & 2 & 10 & 7 & 25 & 12 \\
\hline $\begin{array}{l}\text { Continuaron entrena- } \\
\text { miento especial }\end{array}$ & 11 & 10 & 5 & 3 & - & 29 & 14 \\
\hline $\begin{array}{l}\text { No continuaron estu- } \\
\text { dios o no se conoce su } \\
\text { destino }\end{array}$ & 11 & 4 & 8 & 5 & 2 & 30 & 15 \\
\hline Suspendidas & 1 & - & - & - & - & - & - \\
\hline Sin informacıón & 2 & 5 & 5 & 11 & - & 23 & 11 \\
\hline TOTAL & 58 & 46 & 38 & 48 & $14^{*}$ & 204 & - \\
\hline
\end{tabular}

* 30 alumnas estaban todavía en el Centro durante este período académico.

Uno de los objetivos que busca el centro con toda alumna que recibe es hacerla consciente sobre su papel de mujer, sobre sus deberes y obligaciones como madre y su responsabilidad ante la sociedad. Un segundo embarazo, poco tiempo después del nacimiento del primer hijo, es hecho común en muchas mujeres jóvenes en Jamaica. De allí la importancia que se asigna a la prevención de tal embarazo en la educación que el centro imparte a las mujeres. El $94 \%$ de 234 estudiantes que fueron admitidas al centro entre abril de 1978 y diciembre de 1979 no había presentado un nuevo embarazo en el mes de marzo de 1980. El porcentaje de uso como es fácil suponerlo se incrementa en forma subs- 
tancial en las participantes a raíz de su contacto en el centro.

Muchos de los presentes estarán preguntándose cuánto cuesta mantener un centro como el aquí descrito y que gastos se hacen.

Menciono en primer lugar la importante contribución que hace el gobierno de Jamaica, representada en el alquiler de la casa que sirve de sede al proyecto, el pago de personal de secretarias encargadas de la guardería, los servicios públi$\cos$ y los gastos administrativos en general, para mantener funcionando el Centro.

\section{Cuadro No. 4}

\section{PRESUPUESTO DEL PROYECTO}

\begin{tabular}{|l|c|c|}
\hline Gasto & Primer Año & Segundo Año \\
\hline Costo Total & US\$18.259 & $\$ 16.255$ \\
\hline Salarios & $33.7 \%$ & $57.2 \%$ \\
Prestaciones Sociales & 5.0 & \\
Honorarios & 9.1 & \\
$\begin{array}{l}\text { Transporte personal } \\
\text { del Centro }\end{array}$ & 2.5 & 4.0 \\
$\begin{array}{l}\text { Equipo y suministros } \\
\text { Ayuda para transporte } \\
\text { de estudiantes/otro } \\
\text { subsidio }\end{array}$ & 13.9 & 3.2 \\
$\begin{array}{l}\text { Auditoría } \\
\text { Remodelación } \\
\text { Instalación física }\end{array}$ & 32.8 & 31.8 \\
\hline
\end{tabular}

- Incluye prestaciones sociales y pago de honorarios.

\section{NOTA:}

El Gobierno de Jamaica contribuyó con el pago del alquiler de la casa, la administración de ésta - Servicios Públicos - Secretarias y encargadas de Guardería.
La contribución de la Fundación Pathfinder para dos años ascendió a cerca de US\$35.000, representados en la forma en que lo muestra el cuadro No.4. Obsérvese como la ayuda para el transporte de las alumnas $y$ otro subsidio representa una contribución importante de este presupuesto.

Uno debe admitir que este tipo de proyectos no solucionan el problema del embarazo en la mujer adolescente. Quizás se requiera de muchas instituciones como esta para ayudar en forma efectiva en una fase del problema que no esta muy cerca de los orígenes del mismo.

Creemos sin embargo que puede contribuirse en algo a la búsqueda de soluciones acordes con la realidad que enfrenta Jamaica, al apoyar iniciativas como la relatada en esta presentación.

\section{Conclusiones y recomendaciones:}

1. Se requieren programas efectivos de educación sexual y prevención del embarazo en la adolescencia, que contribuyan a limitar la frecuencia con que éste se manifiesta en muchos países del área Latinoamericana.

2. El modelo presentado puede servir de ejemplo para países en los cuales el embarazo en la adolescencia constituye un problema.

3. Se reconoce la importancia que debe otorgársele a la adolescente embarazada.

4. Se resalta la labor adelantada por el personal encargado del proyecto cuya iniciativa y dedicación fueron determinantes para lograr el éxito alcanzado.

5. Se señala la conveniencia de la asociación del gobierno a esta iniciativa. 


\section{A CENTER TO TREAT PREGNANT ADOLESCENTS}

\section{Conclusions and recomendations:}

1. It is necessary to implement effective programs regarding sexual education and pregnancy prevention during adolescence, so as to limit the pregnancy frecuency recorded in many Latin American countries.

2. The pattern showed can be used as an example in those countries where pregnancy during adolescence is a problem.

3. The importance to be given to pregnant adolescents is recognized.

4. Special attention is given to the job carried out by the personnel in charge of the project, whose initiative and dedication were of the outmost im- portance in the achievement of the success obtained.

5. The convenience of the association by the government with this initiative is underlined.

\section{Epilogo}

El Gobierno de Jamaica con el auspicio de las Naciones Unidas, decidió continuar las actividades en favor de la adolescente embarazada financiando el Centro al finalizar el apoyo de la Fundación Pathfinder.

Se han creado desde entonces dos centros más en la capital y en una región fuera de esta, en áreas en donde el problema se manifiesta en características particularmente severas. 